\title{
Kinetics, isotherm and thermodynamics of sterol adsorption on styrene-divinylbenzene anion-exchange resins
}

\author{
Chinakrit Ladadok ${ }^{\mathrm{a}}$, Takehiro Yamaki ${ }^{\mathrm{b}}$, Keigo Matsuda ${ }^{\mathrm{c}}$, Hideyuki Matsumoto ${ }^{\mathrm{d}}$, \\ Duangkamol Na-Ranong ${ }^{\mathrm{a}, *}$ \\ a Department of Chemical Engineering, Faculty of Engineering, \\ King Mongkut's Institute of Technology Ladkrabang, 1, Chalongkrung 1, Ladkrabang, Bangkok \\ 10520 Thailand \\ b National Institute of Advanced Industrial Science and Technology, \\ Research Institute for Chemical Process Technology, 1-1-1 Higashi, Tsukuba, Ibaraki Japan \\ c Department of Chemistry and Chemical Engineering, Graduate School of Science and Engineering, \\ Yamagata University, 4-3-16, Jonan, Yonezawa-shi, Yamagata 992-8510 Japan \\ d Department of Chemical Science and Engineering, School of materials and Chemical Technology, \\ Tokyo Institute of Technology, 2-12-1 Ookayama, Meguro-ku, Tokyo 152-8552 Japan
}

*Corresponding author, e-mail: dnaranong@hotmail.com, duangkamol.na@kmitl.ac.th

Received 9 Jan 2018

Accepted 19 Nov 2018

\begin{abstract}
Phytosterols can be recovered from natural resources using molecular distillation, cold crystallization, which require large energy consumption. Adsorption was considered as a feasible alternative method. In this study, kinetics, isotherm and thermodynamics of stigmasterol adsorption on styrene-divinylbenzene with two different functional groups, strong base (SB-R) and weak base (WB-R), were investigated using a model solution of stigmasterol in $n$-heptane. Isothermal adsorption experiments were performed in temperature range of $298-313 \mathrm{~K}$ and concentration range of $0.3-6.0 \mathrm{mg} / \mathrm{g}_{\mathrm{sol}}$. For both SB-R and WB-R cases, kinetics of adsorption was analysed based on pseudofirst-order and pseudo-second-order models and the results revealed that pseudo-second-order model agreed with the experimental data much better than pseudo-first-order model. Analysis of isotherm data based on Langmuir, Freundlich and linear models showed that Freundlich was the best model that could predict behaviour of sterol adsorption for both SB-R and WB-R cases. In addition, thermodynamics parameters $(\Delta G, \Delta H$ and $\Delta S)$ indicated that the sterol adsorptions on these adsorbents were spontaneous, exothermic and favourable at low temperature.
\end{abstract}

KEYWORDS: adsorbent, ion-exchange resin, phytosterols, separation

\section{INTRODUCTION}

Deodorizer distillate (DD) is a major byproduct from vegetable oil refinery. It consists of free fatty acids (FFA), monoglycerides, diglycerides, triglycerides (TG) and small amount of some bioactive compounds ${ }^{1}$. The amount of FFA in DD ranges from 25-82.5 wt\% depending on type of vegetable oil, refining method and condition ${ }^{2}$. In South East Asian, palm oil production scale has dramatically increased and about 3 million tons of palm fatty acid distillate (PFAD) was annually generated in 2014$2016^{3,4}$. To make overall process more economical reasonable, PFAD could be considered as a resource of phytonutrients such as tocopherols, squalene and sterols $^{2}$.

Sterols have been widely used in food, cos- metics and pharmaceutical industries due to their beneficial bioactivities ${ }^{5}$. As summarized in previous review $^{5}$, two approaches have been mainly used to recover sterols from DD in industry. In one approach, FFA in DD was saponified and the resulted soap was removed from the obtained mixture by simple solid-liquid separation. In the last step, either vacuum distillation or cold crystallization was applied to separate sterols from the unsaponifiable liquid mixture ${ }^{6-8}$. In another approach, FFA and glycerides in DD were transformed to fatty acid alkyl esters (FAAE) via esterification and transesterification $^{9-11}$. After the reactions, multi-step of vacuum distillation or molecular distillation was applied to remove large fraction of FAAE. Cold crystallization was applied as the last step of sterol 
Table 1 Properties of adsorbents

\begin{tabular}{lcc}
\hline Properties & SB-R & WB-R \\
\hline Commercial name & Lewatit Monoplus MP 800 & Lewatit Monoplus MP 68 \\
Type & Strong base macroporous & Weak base macroporous \\
Functional group & Quaternary amine, type I & Tertiary/quarternary amine \\
Matrix structure & Crosslinked polystyrene & Crosslinked polystyrene \\
Bead size (mm) & $0.65( \pm 0.05)$ & $0.54( \pm 0.05)$ \\
Total exchange capacity (min.eq/1) & 0.8 & 1.3 \\
Operating pH range & $0-12$ & $0-7$ \\
Operating temperature $\left(\max .{ }^{\circ} \mathrm{C}\right)$ & 70 & 70 \\
\hline
\end{tabular}

isolation. Moreira and Baltanás ${ }^{10}$ focused on cold crystallization in recovery of sterols from sunflower oil DD. DD was pretreated by transformation of FFA and TG to fatty acid ethyl esters and vacuum distillation at $1.3 \mathrm{mbar}, \leqslant 200^{\circ} \mathrm{C}$. The obtained mixture was then crystallized under wide range of operating conditions. Sterols (84\%) with purity of $36 \%$ was obtained at the optimized condition (mass ratio of solvent to preconcentrated mixture at 4 , cooling rate of $-20^{\circ} \mathrm{C} / \mathrm{h}$ to $-5^{\circ} \mathrm{C}$, ripening time $=$ $22 \mathrm{~h}, 2.5 \mathrm{wt} \%$ of ethanol in hexane). An alternative method to directly isolate sterols from FAME matrices without vacuum distillation at high temperature was used to prevent dissociation of sterols and reduce energy consumption of the overall recovery process $^{12}$. Crystallization was performed in FAME and the obtained solid was washed with hexane. Another $35-42 \%$ of sterols were recovered from sunflower oil DD at the best condition of crystallization $\left(-5^{\circ} \mathrm{C}, 24 \mathrm{~h}\right)$. Although these approaches have been successfully applied to recover sterols from DDs, the processes face major problem of extensive energy requirement; vacuum distillation is usually operated at $1 \times 10^{-3}$ to 1.33 mbar and 140 $300^{\circ} \mathrm{C}$ to vaporize large quantity of the undesired compounds $^{8-10}$ and cold crystallization is usually operated at low temperature $\left(-20 \text { to } 15^{\circ} \mathrm{C}\right)^{6,7,13}$.

Adsorption-desorption was considered as an alternative method for sterol recovery ${ }^{14-16}$. Activated carbon, carbonaceous pyropolymer or magnesium silicate could be used as adsorbents and chlorobenzene, toluene or methyl-t-butyl ether could be used as desorbents. By applying this adsorptiondesorption, sterols were successfully recovered from feed mixtures with wide range of sterol concentrations (14-84 wt\%), with high recovery portion (5095\%). The obtained sterols had reasonably high purity (58-78\%), or even as high as 95\% when the feed mixture was appropriately pretreated by liquidliquid extraction.
In this study, styrene-divinylbenzene copolymer anion-exchange resins with different functional groups, a strong base resin (SB-R) with quaternary amine group and a weak base resin (WB-R) with both quaternary and tertiary amine groups, were considered as attractive adsorbents based on their chemical resistance and simplicity of operation. The main objective of this study was to investigate behaviour of sterol adsorption on these resins. Although there are several types of sterols (i.e., campesterol, stigmasterol and $\beta$-sitosterol) in PFAD, a model solution of stigmasterol in $n$ heptane was used to avoid competitive adsorptions of these sterols and the difficulty in data interpretation. Isothermal batch adsorption was performed to evaluate adsorption capacities of both resins and kinetics of sterol adsorption were further evaluated based on pseudo-first-order and pseudosecond-order models. In addition, adsorption data at equilibrium were analysed based on Langmuir, Freundlich and linear isotherms and three important thermodynamics parameters (i.e. Gibb's free energy change: $\Delta G$, enthalpy change: $\Delta H$ and entropy change: $\Delta S$ ) were calculated. Finally, the adsorption behaviour was discussed based on the calculated thermodynamics parameters.

\section{MATERIALS AND METHODS}

\section{Materials}

To comparatively evaluate performance of phytosterol adsorption on a weak base and a strong base adsorbents, styrene-divinylbenzene copolymer anion-exchange resins with quaternary amine (Lewatit Monoplus MP 800) and tertiary-quaternary amine (Lewatit Monoplus MP 68) functional groups provided by Lanxess were selected as representatives of a weak and a strong base ion exchange resins (WB-R and SB-R), respectively. Table 1 summarizes the characteristic properties of these two adsorbents. To remove moisture from the adsorbents, 
the adsorbents were dried in an oven at $60^{\circ} \mathrm{C}$ under vacuum condition for $6 \mathrm{~h}$ and stored in a desiccator before being used in adsorption experiment. Prior to the adsorption experiment, the adsorbents were washed with $n$-propanol and $n$-hexane.

Stigmasterol supplied by Tama Biochemical Co. Ltd. and $n$-heptane (AR grade) supplied by Apex Chemicals Co. Ltd. were used in the preparation of a model solution of phytosterol containing mixture. Cholesterol supplied from Sigma-Aldrich Inc. was used as an internal standard (ISTD) in quantitative analysis of stigmasterol. HPLC grade organic solvents (methanol, acetonitrile and water supplied from RCI Labscan Ltd. and acetic acid supplied from Merck Ltd.) were used in the quantification of stigmasterol without purification.

\section{Batch adsorption}

To study kinetics, isotherm and thermodynamics of stigmasterol adsorptions on WB-R and SB-R, isothermal batch adsorption were performed using a model solution of stigmasterol in $n$-heptane. Adsorption temperature and stigmasterol concentration were varied in the ranges of $298-313 \mathrm{~K}$ and $0.3-6.0 \mathrm{mg} / \mathrm{g}_{\text {sol }}$, respectively. The model solution $(50 \mathrm{ml})$ and the adsorbent $(5 \mathrm{wt} \%)$ were heated and shaken in an orbital shaker (4000ic; IKA) at $200 \mathrm{rpm}$ for $2 \mathrm{~h}$. Before and after the adsorption, samples $(200 \mu \mathrm{l})$ were taken and filtered through a $0.45 \mu \mathrm{m}$ nylon filter and used for the quantitative analysis of stigmasterol content.

\section{Quantitative analysis}

The content of stigmasterol in the sample was analysed using a high performance liquid chromatograph (HPLC) equipped with a UV detector. An injection valve connected with a sample loop $(20 \mu \mathrm{l})$ was used to introduce the sample into the HPLC. Peak separation was achieved using a reverse-phase column (Inertsil C8-3; $5 \mu \mathrm{m}$ particle diameter, $250 \mathrm{~mm}$ length, $4.6 \mathrm{~mm}$ i.d., GL Sciences Inc). Composition of mobile phase and condition of analysis were adapted from the work reported ${ }^{17}$. Mobile phase was a mixture of acetonitrile (85\%), methanol (5\%), and water containing $1 \%$ of acetic acid $(10 \%)$. The analysis was performed at the flowrate of $1.3 \mathrm{ml} / \mathrm{min}$ at the wavelength of $210 \mathrm{~nm}$. It should be noted that the sample obtained from the batch adsorption experiment was not completely dissolved in the mobile phase, therefore methanol was used as a solvent in HPLC analysis. Cholesterol was used as an internal standard.
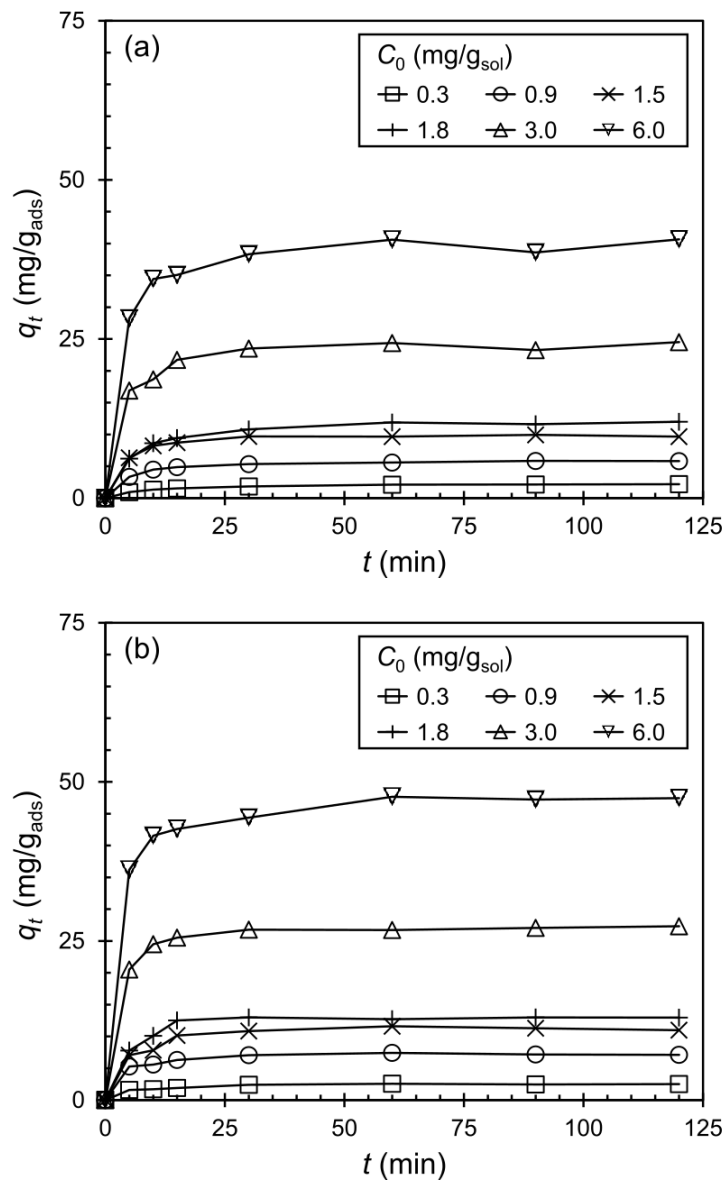

Fig. 1 Adsorption capacities of stigmasterol on (a) SB$\mathrm{R}$ and (b) WB-R versus adsorption time at $303 \mathrm{~K}$ and 5 $\mathrm{wt} \%$ of adsorbent loading for various initial stigmasterol concentrations.

Amount of stigmasterol adsorbed on the adsorbent at time $t\left(q_{\mathrm{t}}\right)$ was calculated according to Eq. (1)

$$
q_{t}=\frac{\left.\left(C_{0}-C_{t}\right)\right) W_{\mathrm{sol}}}{W_{\mathrm{ads}}}
$$

where $C_{0}$ and $C_{\mathrm{t}}$ are liquid-phase concentration of stigmasterol at initial and at time $t$, respectively. $W_{\text {sol }}$ is the weight of the solution and $W_{\text {ads }}$ is the weight of adsorbent used.

\section{RESULTS AND DISCUSSION}

\section{Adsorption capacities}

Fig. 1 shows time dependences of adsorption capacity of SB-R and WB-R at $303 \mathrm{~K}$ and $5 \mathrm{wt} \%$ of adsorbent loading for various initial concentrations of stigmasterol. For both SB-R and WB-R cases, adsorption rapidly occurred in the initial period and af- 
ter 5 min of adsorption the rate of adsorption gradually decreased while the adsorption equilibrium was approached. In the tested range, adsorption reached the equilibrium within $30 \mathrm{~min}$ for all the initial concentrations. Comparison of the profiles obtained at different initial concentrations revealed that the rates of adsorption on both resins increased with the increase of concentration of stigmasterol. This observation could be explained as a result of the increase of concentration leading to increase in the driving force to overcome overall mass transfer resistance of adsorption process ${ }^{18}$. By increasing the initial concentration of stigmasterol from 0.3$6.0 \mathrm{mg} / \mathrm{g}_{\text {sol }}$, in the case of SB-R, the adsorption capacity at the equilibrium $\left(q_{\mathrm{e}}\right)$ increased from 2.15$39.96 \mathrm{mg} / \mathrm{g}_{\text {ads }}$. On the other hand, in the case of WB-R, $q_{\mathrm{e}}$ increased from $2.51-47.44 \mathrm{mg} / \mathrm{g}_{\text {ads }}$. The adsorption capacity at the equilibrium of WB-R was approximately 1.2 times higher than SB-R.

\section{Adsorption kinetics}

To study the kinetics of adsorption, the experimental data were comparatively analysed based on pseudofirst-order and pseudo-second-order models which are expressed as Eqs. (2) and (3), respectively ${ }^{19,20}$.

$$
\begin{aligned}
\frac{d q_{\mathrm{t}}}{d t} & =k_{1}\left(q_{\mathrm{e}}-q_{\mathrm{t}}\right) \\
\frac{d q_{\mathrm{t}}}{d t} & =k_{2}\left(q_{\mathrm{e}}-q_{\mathrm{t}}\right)^{2}
\end{aligned}
$$

$q_{\mathrm{e}}$ and $q_{\mathrm{t}}$ are the amounts of stigmasterol adsorbed at equilibrium and at time $t$, respectively. $k_{1}$ and $k_{2}$ are the adsorption rate constant of pseudo-firstorder and pseudo-second-order model, respectively. Linearized forms of these two models obtained by integrating Eqs. (2) and (3) with the boundary conditions of $q_{\mathrm{t}}=0$ at $t=0$ and $q_{\mathrm{t}}=q_{\mathrm{t}}$ at $t$ are expressed as Eqs. (4) and (5), respectively.

$$
\begin{aligned}
\ln \left(q_{\mathrm{e}}-q_{\mathrm{t}}\right) & =\ln q_{\mathrm{e}}-k_{1} t, \\
\frac{t}{q_{\mathrm{t}}} & =\frac{1}{k_{2} q_{\mathrm{e}}^{2}}+\frac{1}{q_{\mathrm{e}}} .
\end{aligned}
$$

Linear plots corresponding to pseudo-first-order and pseudo-second-order models for SB-R are shown in Fig. 2(a) and Fig. 2(b), respectively. The parameters, $k$ and $q_{\mathrm{e}}$, of each model were calculated from the slope and the y-intercept of the corresponding linear plot and summarized in Table 2 . As shown in the table, the correlation coefficients $\left(R^{2}\right)$ of pseudo-second-order model were higher than those of pseudo-first-order model for all conditions. The
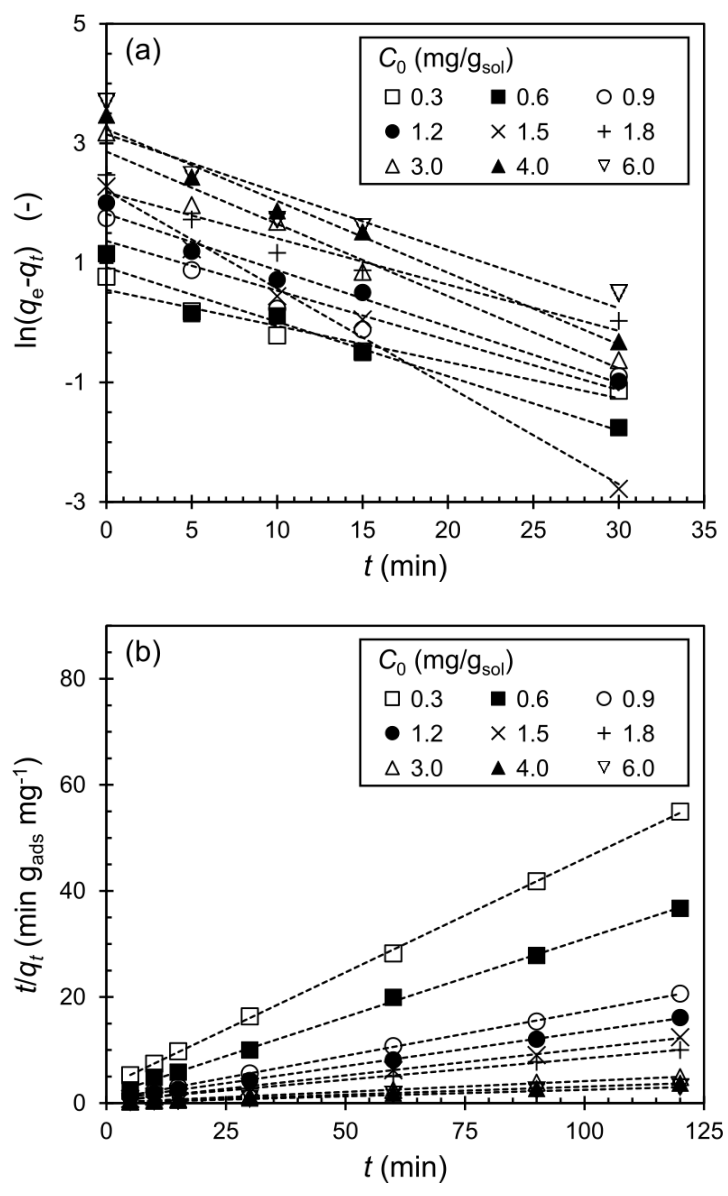

Fig. 2 Linear plots of (a) pseudo-first-order and (b) pseudo-second-order kinetics models for SB-R at 303 $K$ and $5 \mathrm{wt} \%$ of adsorbent loading for various initial stigmasterol concentrations.

lowest value of $\mathrm{R}^{2}$ obtained from pseudo-secondorder model was 0.9986 while the highest value of $\mathrm{R}^{2}$ obtained from pseudo-first-order model was 0.9899. Furthermore, $q_{\mathrm{e}, \text { cal }}$ from pseudo-secondorder model agreed reasonably well with $q_{\mathrm{e} \text { exp }}\left(\Delta q_{\mathrm{e}}\right.$ $<8 \%$ ) while pseudo-first-order model could not well predict the value of $q_{\mathrm{e} \text {,exp }}$. Based on the correlation coefficients and $\Delta q_{\mathrm{e}}$, pseudo-secondorder model was selected to describe the kinetics of stigmasterol adsorption on SB-R. In the case of adsorption on WB-R, similar linear plots corresponding to the two kinetics models were obtained, as shown Fig. 3. The calculated parameters of each model were also summarized in Table 2 . The results revealed that $R^{2}$ of pseudo-second-order model was higher than $\mathrm{R}^{2}$ of pseudo-first-order model and $\Delta q_{\mathrm{e}}$ of pseudo-second-order was less than $\Delta q_{\mathrm{e}}$ of 
Table 2 Kinetic parameters of stigmasterol adsorptions on SB-R and WB-R at $303 \mathrm{~K}$ with different initial concentrations.

\begin{tabular}{|c|c|c|c|c|c|c|c|c|c|c|}
\hline \multirow{2}{*}{ Adsorbents } & \multirow{2}{*}{$\begin{array}{c}C_{0} \\
\left(\mathrm{mg} / \mathrm{g}_{\mathrm{sol}}\right)\end{array}$} & \multirow{2}{*}{$\begin{array}{c}q_{\mathrm{e}, \exp } \\
\left(\mathrm{mg} / \mathrm{g}_{\mathrm{ads}}\right)\end{array}$} & \multicolumn{4}{|c|}{ Pseudo-first-order } & \multicolumn{4}{|c|}{ Pseudo-second-order } \\
\hline & & & $k_{1}\left(\min ^{-1}\right)$ & $q_{\mathrm{e}, \mathrm{cal}}\left(\mathrm{mg} / \mathrm{g}_{\mathrm{ads}}\right)$ & $\Delta q_{e}(\%)$ & $\mathrm{R}^{2}$ & $k_{2}^{\dagger}$ & $q_{\mathrm{e}, \mathrm{cal}}^{\diamond}$ & $\Delta q_{\mathrm{e}}(\%)$ & $\mathrm{R}^{2}$ \\
\hline \multirow[t]{9}{*}{ SB-R } & 0.3 & 2.1529 & 0.0605 & 1.7319 & 19.6 & 0.9475 & 0.0585 & 2.3272 & 7.5 & 0.9997 \\
\hline & 0.6 & 3.1703 & 0.0911 & 2.5199 & 20.5 & 0.9628 & 0.0588 & 3.3898 & 6.5 & 0.9988 \\
\hline & 0.9 & 5.7515 & 0.0832 & 3.9240 & 31.8 & 0.9121 & 0.0446 & 6.0168 & 4.4 & 0.9998 \\
\hline & 1.2 & 7.4262 & 0.0943 & 6.1688 & 16.9 & 0.9804 & 0.0312 & 7.7640 & 4.4 & 0.9996 \\
\hline & 1.5 & 9.7616 & 0.1637 & 9.0948 & 6.8 & 0.9899 & 0.0531 & 9.9502 & 1.9 & 0.9993 \\
\hline & 1.8 & 11.8279 & 0.0772 & 8.8401 & 25.3 & 0.9413 & 0.0179 & 12.4069 & 4.7 & 0.9994 \\
\hline & 3.0 & 24.0448 & 0.1209 & 17.4842 & 27.3 & 0.9694 & 0.0175 & 24.6914 & 2.6 & 0.9986 \\
\hline & 4.0 & 32.1690 & 0.1200 & 25.4191 & 21.0 & 0.9829 & 0.0121 & 33.0033 & 2.5 & 0.9995 \\
\hline & 6.0 & 39.9560 & 0.0970 & 23.3617 & 41.5 & 0.8892 & 0.0115 & 40.8163 & 2.1 & 0.9987 \\
\hline \multirow[t]{9}{*}{ WB-R } & 0.3 & 2.5126 & 0.0984 & 2.1308 & 15.2 & 0.9607 & 0.1012 & 2.6001 & 3.4 & 0.9984 \\
\hline & 0.6 & 4.8633 & 0.2711 & 7.5210 & 35.3 & 0.9765 & 0.1199 & 4.9628 & 2.0 & 0.9998 \\
\hline & 0.9 & 7.2292 & 0.1151 & 5.1841 & 28.3 & 0.9623 & 0.0787 & 7.2939 & 0.9 & 0.9990 \\
\hline & 1.2 & 8.8029 & 0.0635 & 5.0957 & 42.1 & 0.7450 & 0.0405 & 8.9445 & 1.6 & 0.9973 \\
\hline & 1.5 & 11.2957 & 0.1059 & 8.6331 & 23.6 & 0.9437 & 0.0377 & 11.4286 & 1.2 & 0.9979 \\
\hline & 1.8 & 12.8865 & 0.2255 & 15.5615 & 17.2 & 0.9333 & 0.0348 & 13.2450 & 2.7 & 0.9994 \\
\hline & 3.0 & 27.0299 & 0.1458 & 16.2031 & 40.1 & 0.9529 & 0.0263 & 27.5482 & 1.9 & 0.9999 \\
\hline & 4.0 & 29.4413 & 0.1429 & 15.4113 & 47.7 & 0.9208 & 0.0429 & 29.5858 & 0.5 & 0.9997 \\
\hline & 6.0 & 47.4444 & 0.0792 & 22.2202 & 53.2 & 0.7337 & 0.0115 & 48.3092 & 1.8 & 0.9998 \\
\hline
\end{tabular}

${ }^{\dagger}=\mathrm{g}_{\text {ads }} \mathrm{mg}^{-1} \mathrm{~min}^{-1} ;^{\diamond}=\mathrm{mg} / \mathrm{g}_{\text {ads }}$

Table 3 Parameters and correlation coefficients for Langmuir, Freundlich and linear models for isotherms of stigmasterol adsorption on SB-R and WB-R.

\begin{tabular}{|c|c|c|c|c|c|c|c|c|c|}
\hline Mod & & Lang & uir: $q_{\mathrm{e}}=\frac{q}{1}$ & $\mathrm{La}_{\mathrm{La}} C_{\mathrm{e}}$ & & eundlich & $K_{\mathrm{F}} C_{\mathrm{e}}^{1 / n}$ & Linea & $\mathrm{e}=K_{\mathrm{Li}} C_{\mathrm{e}}$ \\
\hline Lin. Eqn & Par & $\frac{C_{\mathrm{e}}}{q_{\mathrm{e}}}=\frac{}{K_{\mathrm{l}}}$ & $-+\frac{1}{q_{\mathrm{m}}} C_{\mathrm{e}}$ &,$q_{\mathrm{m}}$ & $\log q$ & $\log K$ & $C_{\mathrm{e}} ; K_{\mathrm{F}}, 1 / n$ & $q_{\mathrm{e}}$ & ${ }_{\mathrm{i}} C_{\mathrm{e}} ; K_{\mathrm{Li}}$ \\
\hline Adsorbents & $T(\mathrm{~K})$ & $K_{\mathrm{La}}^{\diamond}$ & $q_{\mathrm{m}}^{b}$ & $\mathrm{R}^{2}$ & $K_{\mathrm{F}}^{\dagger}$ & $1 / n$ & $\mathrm{R}^{2}$ & $K_{\mathrm{Li}}^{\sharp}$ & $\mathrm{R}^{2}$ \\
\hline SB-R & 298 & -0.0094 & $-1,250.0$ & 0.0055 & 12.11 & 1.0690 & 0.9698 & 11.91 & 0.8822 \\
\hline & 303 & -0.0552 & -153.8 & 0.2036 & 9.30 & 1.1333 & 0.9794 & 10.09 & 0.9438 \\
\hline & 308 & -0.0524 & -158.7 & 0.1732 & 9.12 & 1.1131 & 0.9744 & 9.89 & 0.9121 \\
\hline & 313 & -0.0491 & -131.6 & 0.1356 & 7.10 & 1.0337 & 0.9510 & 7.88 & 0.9752 \\
\hline WB-R & 298 & 0.0104 & $1,250.0$ & 0.0142 & 12.83 & 0.9727 & 0.9887 & 12.87 & 0.9797 \\
\hline & 303 & 0.0613 & 238.1 & 0.2782 & 13.48 & 0.9258 & 0.9836 & 12.34 & 0.9557 \\
\hline & 308 & -0.0785 & -114.9 & 0.3173 & 10.25 & 1.1785 & 0.9845 & 11.53 & 0.9589 \\
\hline & 313 & -0.0452 & -212.8 & 0.1966 & 10.35 & 1.0721 & 0.9811 & 11.20 & 0.9611 \\
\hline
\end{tabular}

Units: ${ }^{\diamond}=\mathrm{g}_{\text {sol }} / \mathrm{mg} ;{ }^{b}=\mathrm{mg} / \mathrm{g}_{\mathrm{ads}} ;{ }^{\dagger}=\mathrm{mg}^{(n-1) / n} \mathrm{~g}_{\text {sol }}{ }^{1 / n} \mathrm{~g}_{\text {ads }}{ }^{-1} ;{ }^{\sharp}=\mathrm{g}_{\text {sol }} / \mathrm{g}_{\text {ads }}$.

pseudo-first-order for all conditions. Hence pseudosecond-order model was selected as the suitable model for describing the kinetics of stigmasterol adsorption on WB-R as well.

For both SB-R and WB-R cases, $k_{2}$ depended on the initial concentration of stigmasterol $\left(C_{0}\right)$. When $C_{0}$ was increased from $0.3-6.0 \mathrm{mg} / \mathrm{g}_{\text {sol }}$, $k_{2, \mathrm{SB}-\mathrm{R}}$ decreased from 0.0585 to 0.0115 while $k_{2, \mathrm{WB}-\mathrm{R}}$ decreased from 0.1012 to $0.0115 \mathrm{~g}_{\mathrm{ads}} \mathrm{mg}^{-1}$ $\mathrm{min}^{-1}$. This dependence of $k_{2}$ on initial concentration was previously reported in several adsorption systems $^{21-23}$. Theoretically analysis by Azizian ${ }^{24}$ clearly showed that $k_{2}$ is not an intrinsic rate constant of adsorption, but it is a complex function of adsorption rate constant, desorption rate constant and initial concentration of adsorbate.

\section{Adsorption isotherm}

Adsorption isotherm was investigated at 298, 303, 308 , and $313 \mathrm{~K}$ and discussed based on the data taken after $1 \mathrm{~h}$ of adsorption, which were reasonably considered as the performance at the equilibrium of 

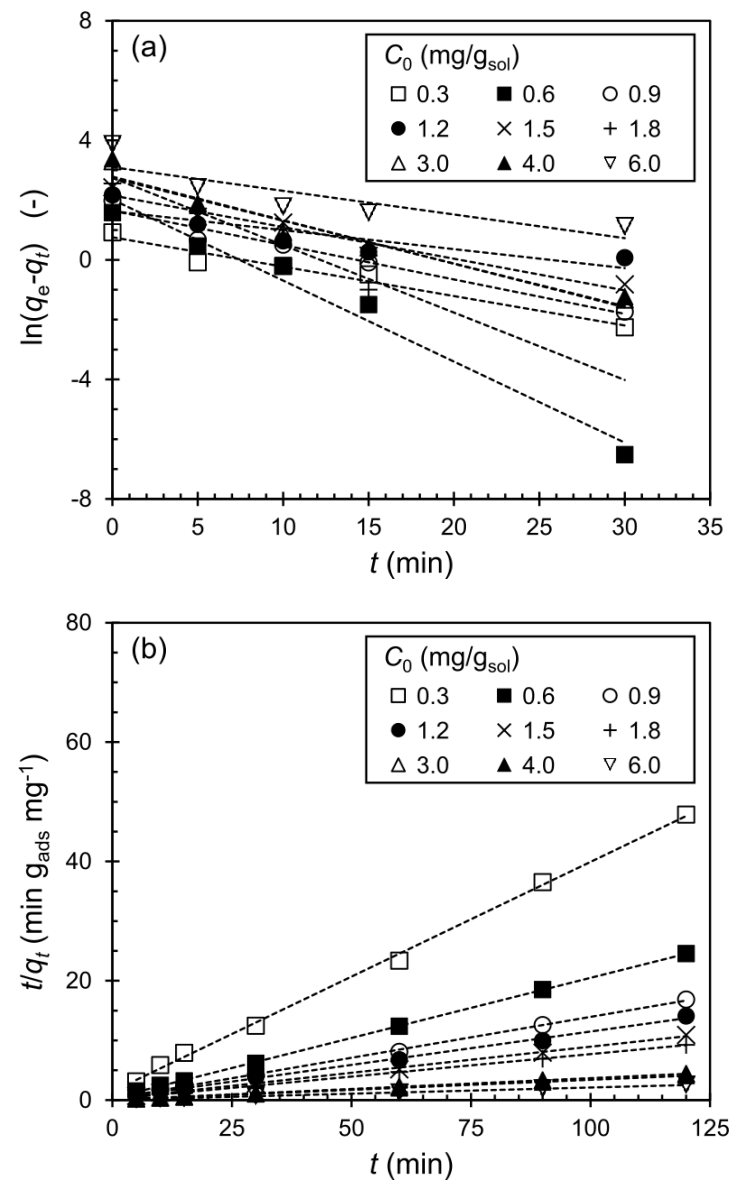

Fig. 3 Linear plots of (a) pseudo-first-order and (b) pseudo-second-order kinetics models for WB-R at 303 $K$ and $5 \mathrm{wt} \%$ of adsorbent loading for various initial stigmasterol concentrations.

adsorption according to the discussion in section of adsorption capacities. Fig. 4 shows dependence of adsorption capacity at the equilibrium $\left(q_{\mathrm{e}}\right)$ on concentration of stigmasterol at the equilibrium $\left(C_{\mathrm{e}}\right)$ at $303 \mathrm{~K}$. For both SB-R and WB-R, in the tested range of $C_{\mathrm{e}}, q_{\mathrm{e}}$ increased with $C_{\mathrm{e}}$ and saturation of adsorption were not observed. Fig. 5 shows effect of temperature on $q_{\mathrm{e}}$ for various initial concentrations. For both SB-R and WB-R, $q_{\mathrm{e}}$ decreased when the temperature was increased. This result indicated that stigmasterol adsorption was exothermic for both SB-R and WB-R cases. It should be noted that this dependence was significant in the case of high initial concentration and became less significant when the initial concentration was lower.

Equilibrium adsorption data were analysed based on Langmuir, Freundlich and linear isotherm
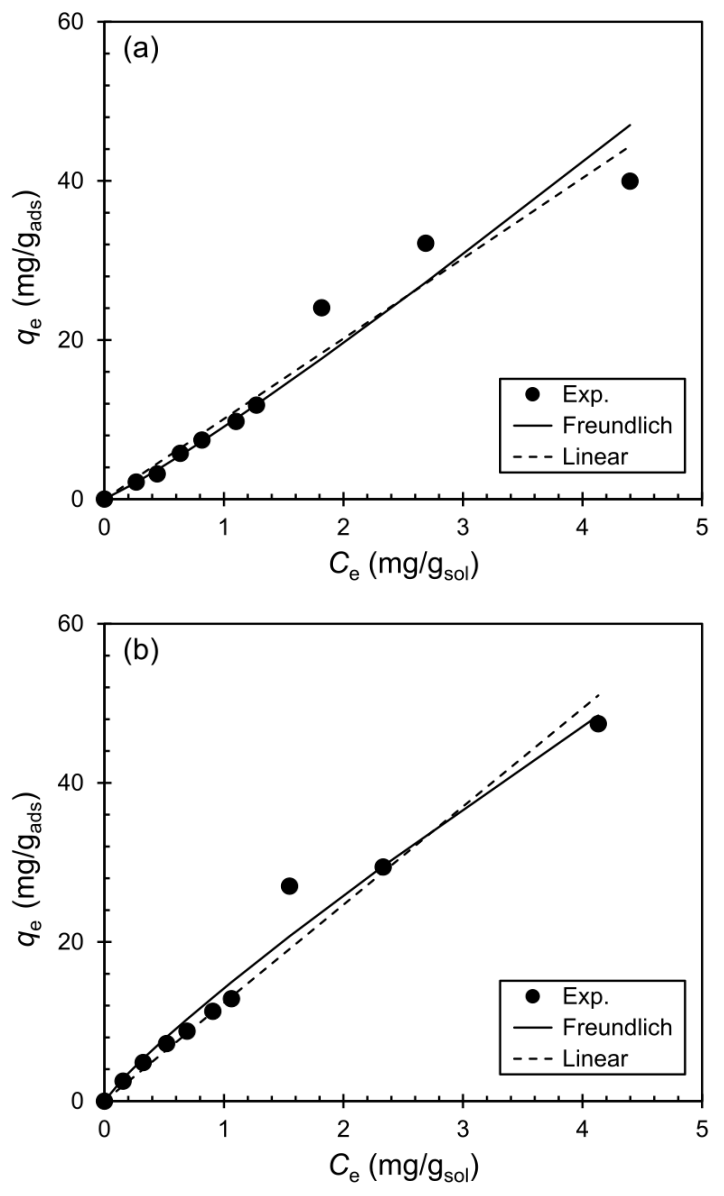

Fig. 4 Dependences of $q_{\mathrm{e}}$ on $C_{\mathrm{e}}$ calculated using Freundlich and linear model comparing with the experimental data for adsorption of stigmasterol on (a) SB-R and (b) WB-R, ( $T=303 \mathrm{~K}$, adsorbent loading $=5 \mathrm{wt} \%)$.

models using the corresponding linearized form of each model, listed in Table 3. Langmuir model was considered as an inappropriate model for prediction of isotherm of stigmasterol adsorption for both SB$\mathrm{R}$ and WB-R since the value of $R^{2}$ was extremely low, the obtained $q_{\mathrm{m}}$ (saturated adsorption capacity) and $K_{\mathrm{La}}$ (Adsorption equilibrium constant in Langmuir model, $\mathrm{g}_{\text {sol }} / \mathrm{mg}$ ) were negative, which had no physical meaning for adsorption process. Since $R^{2}$ of Freundlich model were larger than $R^{2}$ of linear model for all conditions, excepting SB-R at $313 \mathrm{~K}$, Freundlich model was considered as the most suitable model to be used to predict the performance of adsorption at the equilibrium for both SB$\mathrm{R}$ and WB-R. However, it should be noted that the calculated values of $1 / n$ were nearly equal to 1 for all conditions, indicating that the concentration of 

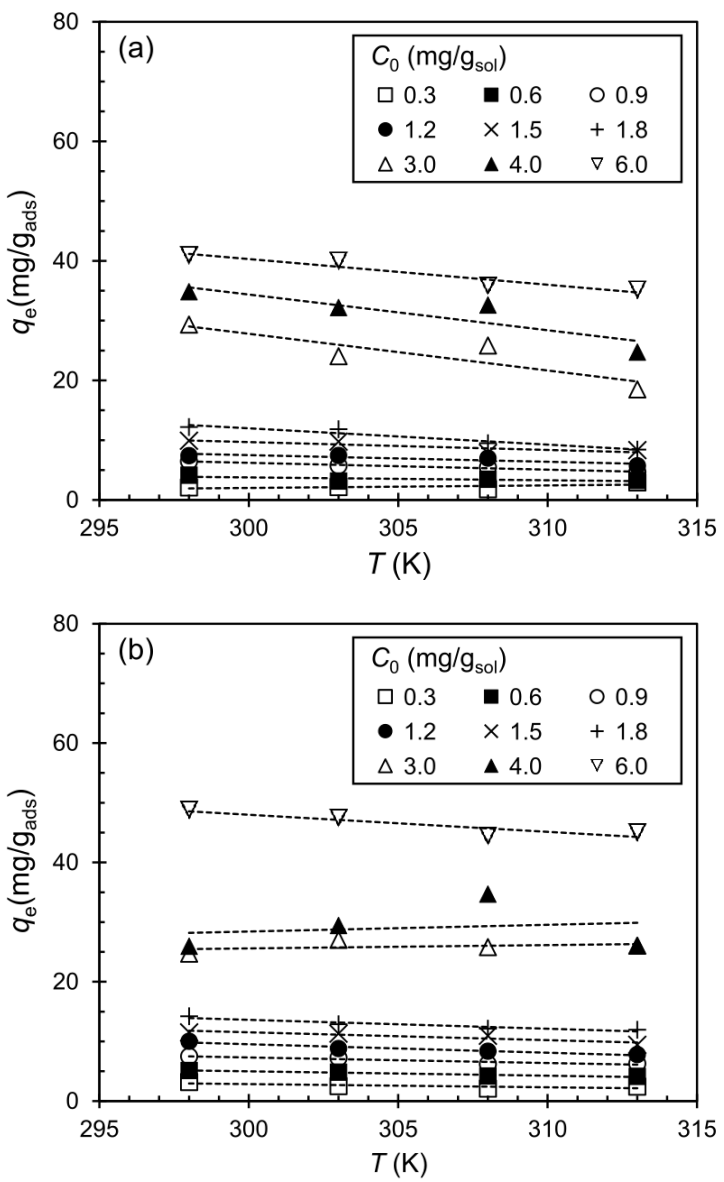

Fig. 5 Effect of temperature on the adsorption capacity of (a) SB-R and (b) WB-R at the equilibrium $\left(q_{\mathrm{e}}\right)$ for various initial stigmasterol concentrations, $(T=298-313$ $K$, adsorbent loading $=5 \mathrm{wt} \%$ ).

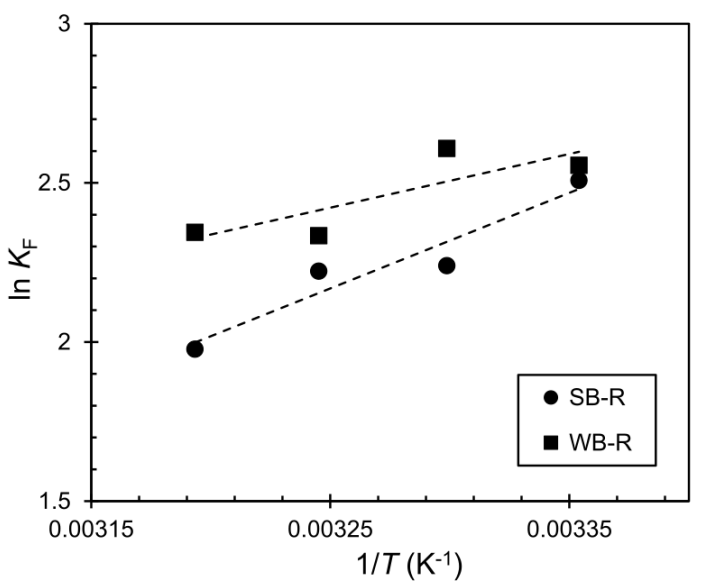

Fig. 6 Plot of $\ln K_{\mathrm{F}}$ versus $1 / T$ for SB-R and WB-R. stigmasterol in overall tested range in this study was low and the adsorption behaved like linear model. In addition, for both SB-R and WB-R cases, the calculated $K_{\mathrm{F}}$ (Adsorption equilibrium constant in Freundlich model $\mathrm{mg}^{(n-1) / n} \mathrm{~g}_{\text {sol }}{ }^{1 / n} \mathrm{~g}_{\text {ads }}^{-1}$ decreased when the temperature of adsorption was increased.

Fig. 4 shows good resemblances of the calculated curves and the experimental data for both Freundlich and linear models. Similar plots (not shown) were obtained at the other temperatures (298, 308, and $313 \mathrm{~K}$ ) and showed good resemblances of the calculated curves and the experimental data, as well. In the case of SB-R (Fig. 4(a)), nonlinear regression analysis was performed for both Freundlich and linear models and gave the same $R^{2}$ (0.9438). Based on regression analysis, Freundlich model was the most suitable model for prediction of effect of $C_{\mathrm{e}}$ on $q_{\mathrm{e}}$ in the tested range of $0<C_{\mathrm{e}}<4.5 \mathrm{mg} / \mathrm{g}_{\text {sol }}$ and $298<T<313 \mathrm{~K}$.

In the case of WB-R, similar results were obtained. Fig. 4 (b) shows that both models show good resemblances of the calculated curves and the experimental data, as well. Regression analysis revealed that Freundlich model was slightly better than linear model (Freundlich model: $\mathrm{R}^{2}=0.9706$; liner model: $\left.\mathrm{R}^{2}=0.9557\right)$. Hence Freundlich model was also the most suitable model for prediction of effect of $C_{\mathrm{e}}$ on $q_{\mathrm{e}}$ in stigmasterol adsorption on WBR.

\section{Adsorption thermodynamics}

To obtain useful information for the design of adsorption process, thermodynamics parameters of adsorption (Gibb's free energy change: $\Delta G$, enthalpy change: $\Delta H$ and entropy change: $\Delta S$ ) were evaluated for both SB-R and WB-R cases. Based on the discussion in section of adsorption isotherm, adsorption equilibrium constants at various temperatures were calculated using Freundlich model and $\Delta G$ and $\Delta S$ were calculated using Eqs. (6) and (7), respectively.

$$
\begin{aligned}
\Delta G & =-R T \ln K_{\mathrm{F}} \\
\ln K^{\mathrm{F}} & =\frac{\Delta S}{R}-\frac{\Delta H}{R T} .
\end{aligned}
$$

By performing linear regression analysis of the plot between $\ln K_{\mathrm{F}}$ and $1 / T$, (Fig. 6), enthalpy change $(\Delta H)$ and entropy change $(\Delta S)$ were calculated from the slope and the y-intercept of the obtained straight line. As summarized in Table 4, for both SB$\mathrm{R}$ and WB-R, adsorption had negative values of $\Delta G$, $\Delta H$, and $\Delta S$. The negative value of $\Delta G$ indicates 
Table 4 Thermodynamics parameters of stigmasterol adsorptions on SB-R and WB-R.

\begin{tabular}{|c|c|c|c|c|c|c|}
\hline \multirow{2}{*}{$T(\mathrm{~K})$} & \multicolumn{3}{|c|}{ SB-R } & \multicolumn{3}{|c|}{ WB-R } \\
\hline & $\begin{array}{c}\Delta G \\
(\mathrm{~kJ} / \mathrm{mol})\end{array}$ & $\begin{array}{c}\Delta H \\
(\mathrm{~kJ} / \mathrm{mol})\end{array}$ & $\begin{array}{c}\Delta S \\
\left(\mathrm{~kJ} \mathrm{~mol}^{-1} \mathrm{~K}^{-1}\right)\end{array}$ & $\begin{array}{c}\Delta G \\
(\mathrm{~kJ} / \mathrm{mol})\end{array}$ & $\begin{array}{c}\Delta H \\
(\mathrm{~kJ} / \mathrm{mol})\end{array}$ & $\begin{array}{c}\Delta S \\
\left(\mathrm{~kJ} \mathrm{~mol}^{-1} \mathrm{~K}^{-1}\right)\end{array}$ \\
\hline 298 & -6.22 & & & -6.20 & & \\
\hline 303 & -5.65 & -2497 & -0.06 & -6.43 & -1403 & -0.03 \\
\hline 308 & -5.69 & -24.91 & -0.00 & -5.85 & -14.03 & -0.03 \\
\hline 313 & -5.15 & & & -5.97 & & \\
\hline
\end{tabular}

that the adsorption is spontaneous and feasible. The increase of $\Delta G$ with respect to temperature indicates that the adsorption is more favourable at lower temperatures $^{25}$. Since the calculated values of $\Delta G$ for both SB-R and WB-R cases were in the range of -20 to $0 \mathrm{~kJ} / \mathrm{mol}$, stigmasterol adsorption on SB-R and WB-R could be considered as physical adsorption $^{26}$. The negative value of $\Delta H$ indicates that the adsorption is exothermic and agreed well with the effect of temperature on adsorption capacity at the equilibrium discussed in section of adsorption isotherm. Comparison of $\Delta H_{\mathrm{SB}-\mathrm{R}}(-24.97 \mathrm{~kJ} / \mathrm{mol})$ and $\Delta H_{\mathrm{WB}-\mathrm{R}}(-14.03 \mathrm{~kJ} / \mathrm{mol})$ indicates that the interaction between stigmasterol and SB-R is stronger than the interaction between stigmasterol and WB$\mathrm{R}$. The negative value of $\Delta S$ indicates associative adsorption and decrease of the randomness between the solid/liquid interface due to the adsorption ${ }^{27,28}$.

\section{CONCLUSIONS}

Analysis of kinetics, isotherm and thermodynamics of stigmasterol adsorption on commercial anion exchange styrene-divinylbenzene resin with strong and weak base functional group (SB-R and WB-R) revealed that both $\mathrm{SB}-\mathrm{R}$ and $\mathrm{WB}-\mathrm{R}$ were promising for separation of phytosterols from sterol containing mixture. Adsorption capacity at equilibrium of stigmasterol on WB-R was higher than SB-R. The adsorption rate of phytosterols on SB-R and WB-R could be described by pseudo-second-order kinetics model. Equilibrium data was well fitted with Freundlich isotherm $\left(\mathrm{R}^{2} \geqslant 0.9510\right)$ and better than Langmuir and linear isotherm models. The thermodynamics parameters indicated that the adsorption on both resins were exothermic and spontaneous processes.

Acknowledgements: This study was supported by National Research Councils of Thailand (NRCT). C. Ladadok gratefully acknowledges Thailand Research Fund and King Mongkut's Institute of Technology Ladkrabang (KMITL) for financial support under Royal Golden Jubilee
Ph.D. program (PHD/0021/2555).

\section{REFERENCES}

1. Verleyen $T$, Verhe $R$, Garcia L, Dewettinck $K$, Huyghebaert A, Greyt WD (2001) Gas chromatographic characterization of vegetable oil deodorization distillate. $J$ Chromatogr A 921, 277-85.

2. Gunawan S, Ju YH (2009) Vegetable oil deodorizer distillate: characterization, utilization and analysis. Sep Purif Rev 38, 207-41.

3. Malaysian Palm Oil Board (2017) Overview of the Malaysian oil palm industry.

4. Richey B, Preechajarn $S$ (2015) Thailand palm oil production supply demand update. US Department of Agriculture TH5074.

5. Fernandes P, Cabral JMS (2007) Phytosterols: applications and recovery methods. Biores Technol 98, 2335-50.

6. Yang H, Yan F, Wu D, Huo M, Li J, Cao Y, Jiang Y (2010) Recovery of phytosterols from waste residue of soya bean oil deodorizer distillate. Bioresour Technol 101, 1471-76.

7. Khatoon S, Rajan RGR, Krishna AGG (2010) Physicochemical characteristics and composition of Indian soya bean oil deodorizer distillate and the recovery of phytosterols. J Am Oil Chem Soc 87, 321-26.

8. Rohr $R$ (2003) Process for separation unsaponifiable valuable products from raw materials. US Patent 2003/0120095 A1.

9. Fizet $C$ (1996) Process for tocopherols and sterols from natural sources. US Patent 5487817.

10. Moreira EA, Baltanás MA (2004) Recovery of phytosterols from sunflower oil deodorizer distillates. JAOCS 81, 161-7.

11. Wollmann G, Schwarzer J, Gutsche B (2005) Processes for producing sterols from fatty acid production residues. US Patent 6956125 B2.

12. Carmona MA, Jiménez $C$, Sanchidrián CJ, Peña $F$, Ruiz JR (2010) Isolation of sterols from sunflower oil deodorizer distillate. $J$ Food Eng 101, 210-13.

13. Smith FE (1967) Separation of tocopherols and sterols from deodorizer sludge and the like. US Patent 3335154.

14. Barder TJ (1989) Purification of sterols with ac- 
tivated carbon as adsorbent and chlorobenzene as desorbent. US Patent 4882065.

15. Barder TJ, Johnson P (1989) Adsorption separation of sterols from tall oil pitch carbon adsorbent. US Patent 4849112.

16. Barder TJ, Bedwell WB, Johnson SP (1990) Separation of sterols from low-acid feeds with magnesium silicate and methyl-tert-butyl ether desorbent. US Patent 4977243.

17. Chang CJ, Chang YF, Lee HZ, Lin JQ, Yang PW (2000) Supercritical $\mathrm{CO}_{2}$ extraction of high-value substances from soya bean oil deodorizer distillate. Ind Eng Chem Res 39, 4521-5.

18. Aksu Z (2001) Biosorption of reactive dyes by dried activated sludge: equilibrium and kinetic modelling. Biochem Eng $J$ 7, 79-84.

19. Lin J, Wang L (2009) Comparison between linear and nonlinear forms of pseudo-first-order and pseudosecond-order adsorption kinetic models for the removal of methylene blue by activated carbon. Front Environ Sci Engin China 33, 320-4.

20. Ho YS, McKay G (1999) Pseudo-second-order model for sorption processes. Process Biochem 34, 451-65.

21. Ho YS, McKay G (1999) Batch lead(II) removal from aqueous solution by peat: equilibrium and kinetics. Trans IChemE 77, 165-73.

22. Hameed BH, Ahmad AL, Latiff KNA (2007) Adsorption of basic dye (methylene blue) onto activated carbon prepared from rattan sawdust. Dyes Pigm 75, 143-9.

23. Chen H, Zhao J (2009) Adsorption study for removal of Congo red anionic dye using organo-attapulgite. Adsorption 15, 381-9.

24. Azizian S (2004) Kinetic models of sorption: a theoretical analysis. $J$ Colloid Interf Sci 276, 47-52.

25. Chu BS, Baharin BS, Man YBC, Quek SY (2004) Separation of vitamin $\mathrm{E}$ from palm fatty acid distillate using silica: I equilibrium of batch adsorption. $J$ Food Eng 62, 97-103.

26. Yu Y, Zhuang YY, Wang ZH (2001) Adsorption of water-soluble dye onto functionalized resin. $J$ Colloid Interf Sci 242, 288-93.

27. Scheckel KG, Sparks DL (2001) Temperature effects on nickel sorption kinetics at the mineral-water interface. Soil Sci Soc Am J 65, 719-28.

28. Rattanaphani S, Chairat $M$, Bremner JB, Rattanaphani V (2007) An adsorption and thermodynamic study of lac dyeing on cotton pretreated with chitosan. Dyes Pigm 72, 88-96. 